Etnográfica

Revista do Centro em Rede de Investigação em

Antropologia

vol. 11 (2) | 2007

Vol. 11 (2)

\title{
Entre games e folgações: apontamentos de uma antropóloga na lan house
}

Between games and folgações. Anthropological notes in the lan house

\section{Vanessa Andrade Pereira}

\section{(2) OpenEdition}

Journals

Edição electrónica

URL: https://journals.openedition.org/etnografica/1989

DOI: 10.4000/etnografica.1989

ISSN: 2182-2891

\section{Editora}

Centro em Rede de Investigação em Antropologia

Edição impressa

Data de publição: 1 novembro 2007

Paginação: 327-352

ISBN: 0873-6561; E-ISBN 2182-2891

ISSN: 0873-6561

\section{Refêrencia eletrónica}

Vanessa Andrade Pereira, «Entre games e folgações: apontamentos de uma antropóloga na lan house», Etnográfica [Online], vol. 11 (2)| 2007, posto online no dia 26 setembro 2012, consultado o 11 fevereiro 2022. URL: http://journals.openedition.org/etnografica/1989; DOI: https://doi.org/10.4000/ etnografica.1989

\section{(c) (i) (9)}

Etnográfica is licensed under a Creative Commons Attribution-NonCommercial 4.0 International License. 


\section{Entre games e folgações: apontamentos de uma antropóloga na lan house}

\section{Vanessa Andrade Pereira}

O objetivo deste artigo é apresentar o processo de aproximação da pesquisadora junto a jovens de uma lan house da cidade de Porto Alegre, RS, Brasil. Visa descrever as características dessa casa de jogo em rede, sua localização no bairro, e o cotidiano dos jovens que a usam para jogar games pela Internet ou apenas como point de sociabilidade. Demonstra como os jovens configuram seus pertencimentos e intensificam seus laços sociais através das "folgações" (jocosidade), e das interações online no game Tibia.

PALAVRAS-CHAVE: redes sociais, lan house, juventude, game, sociabilidade, Internet.

O Tibia é divertido se tiver gente, quando o jogo tem muita gente junto, aí fica mais legal. Jogar sozinho não tem graça. (Madruga)

Welcome, wanderer, to the fascinating world of Tibia, a massive multiplayer online role playing game. Take the role of a valorous adventurer, explore a huge realm of magic and mystery and make friends with people from all over the world! (www.tibia.com)

O AMBIENTE É SOTURNO, UMA SALA ESCURA, PAREDES PINTADAS DE azul marinho e prateado. $\mathrm{O}$ ar é artificial, beirando sempre os $20^{\circ} \mathrm{C}$ temperados pelo enorme ar condicionado interno. A luz apagada e o brilho hipnótico dos monitores ilumina os rostos absortos.

A primeira vez que entrei na X-play Lan House não tinha intenção alguma de firmar meu campo por ali. Meu computador havia estragado e eu estava à procura de um local para ler meus e-mails e ter acesso à Internet.

A escuridão da sala incomodava-me, embora me desse uma sensação de privacidade que logo foi quebrada pela quantidade de transeuntes por detrás de minha cadeira, falantes e observadores das telas. Os gritos e xingamentos entre os jovens que jogavam games, impediam que me concentrasse nos meus 
afazeres digitais e, acima de tudo, eu considerava um "desrespeito" estarem aos berros num lugar em que nem todos estavam realizando a mesma atividade. Lembro-me de diversas vezes ter lançado olhares fulminantes para alguns dos jovens envolvidos na algazarra, olhares que eram frustrados, pois eles não desgrudavam os olhos dos monitores.

Meu computador permaneceu estragado por quase um mês e eu me via obrigada a freqüentar a lan house diariamente para acessar a Internet. Escolhia ir ao início da tarde, na esperança de que não houvesse muitos jovens jogando mas, para minha insatisfação, eles estavam sempre lá, em qualquer horário, ao menos um, e esse um, mesmo que mais contido, seguia as mesmas ações de seus amigos e, a qualquer momento, um grito tirava-me de minha serena concentração: "AAAAHHHH, VOU MORRER, VOU MORRER!" "VEM, MEU, VEM, ELES VÃO ME MATAR!!!... VEM LOGO".

A situação piorava muito quando era um grupo de quatro ou mais pessoas jogando. Mas foi justamente num dia de grande euforia (para mim, desespero total) em função dos games que parei de redigir um e-mail, deixei o tempo do "timer" (programa controlador de gasto) da lan correr, levantei-me de minha cadeira, na tentativa de ser vista, e decidi que faria alguma reclamação. Eles estavam completamente absortos nos vídeos, com fones nos ouvidos e inteiramente vidrados no jogo. Certamente não perceberam que uma cabeça se sobressaía sobre um monitor no fundo, e obviamente não teriam ouvido nada além dos barulhos digitais dos "golpes e contragolpes" que soavam em seus fones de ouvido.

Fiquei observando o que se passava, tentando entender aquela gritaria, aquele monte de jovens entrando e saindo, caminhando pela sala. Naquele instante, a minha perturbação virou curiosidade antropológica. Foi como se eu tivesse tomado um "choque" aos moldes de Schutz. ${ }^{1}$

O computador que, no meu entendimento, era algo privado, solitário e de relação quase que em simbiose mental e silenciosa entre sujeito e máquina, de repente estava sendo usado em grupo com tanta excitação, gritaria, agito e comoção. A primeira observação mais apurada, ainda com a cabeça esticada sobre o monitor, permitiu-me observar que os jogadores eram jovens, todos homens, com muita afinidade uns com os outros. Xingavam-se constantemente, mas não havia agressão física e riam muito. As meninas apenas "rondavam" os micros (gíria referente à palavra "microcomputador"), conversavam entre si, entravam e saíam e, quando usavam as máquinas, não era por mais do

I Para Schutz passamos a entender os sistemas simbólicos dos outros através de um choque que se procede da seguinte maneira: a realidade que nos parece ser "natural" em forma de "realidade suprema" (da qual não temos dúvida) nos mantém dentro de nossa província finita de significado até que vivenciamos um choque que nos leva a romper os limites dessa província, e propõe mudar o acento dessa realidade para outra. O que acontece no "choque" é "uma modificação radical da tensão de nossa consciência, fundamentada num tipo diferente de attention à la vie." (1979: 252). 
que trinta minutos. Elas, ao contrário deles, não eram capazes empenharem-se horas jogando. Os atendentes do estabelecimento, muito menos profissionais do que eu esperaria de um "serviço", eram também jovens e compartilhavam dos games, o que por vezes tornava a lan um território de total liberdade juvenil.

\section{LAN HOUSE}

LAN significa local area network, ou seja, define um local onde vários computadores estão interligados. A expressão lan house pode ser traduzida para "casa de computadores em rede", ou "casa de jogos em rede". As lan houses são ambientes que disponibilizam computadores de alta tecnologia conectados à Internet e preparados para jogos digitais em rede. Os micros também contam com fones de ouvido, mouses e teclados, indispensáveis para uma boa performance nos games. Os computadores são dispostos lado a lado sem divisórias entre eles, diferenciando-os dos "cibercafés" que são direcionados para uso privado e discreto da Internet e não de jogos online. ${ }^{2}$

As lan houses são um fenômeno recente, de acordo com dados da Internet as lan houses surgiram na Coréia do Sul em 1996. A idéia foi trazida para o Brasil em 1998 por Sunami Chun, então com 21 anos. Chun é diretor da Monkey, de São Paulo, a primeira lan house brasileira, uma franquia que em Agosto de 2005 contabilizava 23 lojas em 7 estados brasileiros e uma no México. ${ }^{3}$

Em Porto Alegre, onde se passa esta pesquisa, as lan houses estão espalhadas por grande parte da cidade. Durante muito tempo o alvará de funcionamento concedido pela prefeitura para serviços deste tipo era como "casas de jogos eletrônicos", o mesmo concedido a casas de fliperama ou bares com máquinas caça-níqueis. Por isso, tornou-se difícil conseguir um dado correto do número de casas na cidade ou de quando o primeiro estabelecimento deste tipo começou a funcionar. Estima-se o número de trinta a cinqüenta casas em toda cidade. ${ }^{4}$

A X-play Lan House, localizada no Bairro Passo do Ipê, numa avenida importante chamada Conde Isidoro, ${ }^{5}$ possui vinte computadores de última geração com monitores de 17 polegadas numa área de $70 \mathrm{~m}^{2}$. A lan house funciona desde 2003, oferecendo outros serviços além dos jogos: acesso à Internet, gravação de imagens de câmera digital para CD, xerox e fax. Porém é mais freqüentada por aqueles que curtem os games online.

2 Sobre uma experiência etnográfica em cibercafés, ver: "Etnografia on e off-line: cibercafés em Trinidad", de Daniel Miller e Don Slater (2004).

3 Fonte: site da Monkey (www.monkey.com.br).

4 Esse número foi estimado em conjunto com os donos da lan (Paulo, Tosco e Léo) e alguns outros usuários, avaliando as unidades de lojas por bairro da cidade.

5 Foram usados nomes fantasias no bairro, ruas e outros lugares referidos no texto. 
A minha aproximação foi lenta. Comecei falando com os proprietários: os irmãos Marcos (17 anos, chamado de Tosco pelos amigos) e Leonardo (24 anos, chamado de Léo), que estavam diariamente no balcão de atendimento da loja e sempre dispostos a conversar. Perguntava sobre a lan, quando a tinham aberto, de quem tinha sido a idéia, se muita gente jogava, e assim fui mantendo contato.

Léo contou-me que a idéia de abrir uma lan house surgiu quando ele percebeu que um amigo estava tendo sucesso com uma loja no centro da cidade de Viamão, região metropolitana de Porto Alegre. Os pais, Marta e Paulo (ambos com 47 anos) possuíam dois veículos de transporte de estudantes ("escolar") e Léo deu a idéia de vender um deles para investir em computadores de última geração e na instalação de uma loja de serviços de games. A primeira lan house foi aberta em Viamão, onde reside a família. Posteriormente surgiu a oportunidade de virem para Porto Alegre. O bairro Passo do Ipê já era conhecido da família porque a avó materna dos meninos reside em um apartamento onde eles passeavam freqüentemente quando crianças. ${ }^{6}$

\section{O BAIRRO PASSO DO IPÊ}

O bairro Passo do Ipê está localizado na zona leste de Porto Alegre, cerca de vinte minutos do centro da cidade. É caracteristicamente residencial, sendo a Avenida Conde Isidoro o ponto principal onde se concentram muitos serviços (sapateiro, restaurantes, gráficas, padarias, petshops, ferragens, lotérica, farmácias, cabeleireiros, lavanderia, etc.), inclusive a X-play Lan House. A construção de um shopping de porte médio em 1998 e da Via Rápida (avenida com $12 \mathrm{~km}$ de extensão que interliga 20 bairros de norte a sul), iniciada em 2000 , têm modificado o perfil do bairro nestes últimos oito anos, impulsionando o comércio e chamando a atenção de construtoras que investem alto na edificação de prédios de apartamentos e condomínios fechados, atraindo um público com poder aquisitivo mais elevado do que era costumeiro antes desse período.

Há um jogo constante entre o processo de modernização e uma permanência do tradicional nos modos de relações e de vivência das pessoas que ocupam o Passo do Ipê. O bairro fica entre dois bairros que contrastam: o Laranjeiras, considerado "zona nobre", e o São Tomás, um bairro que poderia ser considerado "de baixa renda". No São Tomás os espaços de moradia são de terrenos de tamanhos desiguais e, mesmo que ainda persistam algumas propriedades

6 Este apartamento da avó de Tosco e Léo era parte de um conjunto habitacional de três blocos, sendo que minha mãe também reside num dos prédios, no qual morei nos seis primeiros meses da pesquisa de campo. Esse fato facilitou muito a aproximação com os jovens, já que tínhamos um espaço de trânsito comum além da lan, encontrando-nos facilmente nas ruas, cruzamentos, supermercados, padarias. 
amplas, poucas casas poderiam ser consideradas "luxuosas". Existem pelos interstícios do bairro pequenas vilas (favelas) onde se sobrepõem casebres feitos de alvenaria, madeira e papelão. O São Tomás conta ainda com duas grandes vilas, a "Sepé" e "Morrinhos". ${ }^{7}$ Já o Laranjeiras ostenta casarões da década de 30 com vastos jardins. Essas grandes e luxuosas residências estão, aos poucos, sendo substituídas por suntuosos prédios de apartamentos de alto valor imobiliário.

É ilustrativa a taxa de rendimento médio mensal de salário mínimo dos domiciliados nos três bairros como representativa do poder aquisitivo dos moradores: 7 salários mínimos no São Tomás, 12 no Passo do Ipê e 20 em Laranjeiras. ${ }^{8}$ O Passo do Ipê é a imagem e o produto da intermediação entre esses dois bairros: nele encontram-se tanto as casas em terrenos conjuntos, quanto residências amplas, embora não tão luxuosas.

Todos os jovens da pesquisa (idade média de 17 anos) residiam nas proximidades da lan house, e tinham o Passo do Ipê como território amplamente demarcado e reconhecido. A Escola Estadual Josué Costa (pública), chamada de "coleginho", era freqüentada pela maioria. Mais do que residir, os jovens apropriam-se simbolicamente do bairro, dando para cada espaço um valor e tornando alguns deles ponto de encontro da sociabilidade juvenil. A X-play Lan House parece ter sido apropriada pelos jovens com este significado, diferente das outras lojas de serviço que são vizinhas da lan: uma vídeo-locadora, um chaveiro e uma padaria. A lan possuía algumas peculiaridades para tanto.

\section{UMA LAN HOUSE NO BAIRRO, NOVO POINT DE SOCIABILIDADE JUVENIL}

Toda sistemática de funcionamento, no que diz respeito a "gestão empresarial" do estabelecimento, não parecia respeitar o padrão de um negócio organizado em função do lucro. Quero dizer com isso que a lan X-play era muito diferenciada em seu funcionamento de todas as outras lans que visitei. Em primeiro lugar, sempre houve a intenção dos donos em ressaltar que era um "ambiente familiar". De fato, a gerência do negócio estava por conta da família: Paulo, Marta e os filhos, Tosco e Léo. O fato da lan estar em um bairro e ser uma loja de rua, com a porta diretamente para a calçada, e não dentro de um shopping ou centro comercial, também fazia com que os freqüentadores mais assíduos fossem os moradores das proximidades, pessoas que já se conheciam de outros âmbitos e que se encontravam também ali. Tosco e Léo, que eram "de fora" do bairro, logo foram incorporados (não sem resistência, veremos depois) como

7 As "vilas" em Porto Alegre correspondem ao que no Rio de Janeiro se chama de "favela". São espaços dentro da cidade que se caracterizam pela falta de urbanização local, convivência diária com situações de violência doméstica, com agentes do tráfico e com a polícia (Piccolo 2003).

8 Fonte: site oficial da Prefeitura de Porto Alegre, referente ao censo de 2000. 
moradores e inseridos numa rede de amizades do bairro. Essa disposição fazia da lan e seus freqüentadores uma "grande família". Gentilezas e favores tornaram-se elementos essenciais nas relações diárias entre os donos e os usuários. Cabe lembrar alguns exemplos: o episódio no qual Tosco deu permissão para um dos amigos dormir por dois dias na lan porque havia se desentendido com os pais; o fato de Mentira (19 anos) ter levado amendoim doce feito por sua mãe para Léo, porque ele gostava muito; Dabota (17 anos) ir à padaria comprar lanche para Tosco; as "festinhas particulares" que faziam, sem o conhecimento de Paulo; Léo ter intercedido junto ao pai para permitir um "clã de CS" que jogaria grátis e representaria a lan; os almoços deliciosos feitos pela avó de Lalau (17 anos) que eram "filados" por Tosco e Léo. ${ }^{9}$

A objetividade das relações mercadológicas "prestador - cliente" era pouco visível. Esse modo objetivo de tratar o cliente só funcionava com aqueles que usavam o computador funcionalmente, jovens desconhecidos ou pessoas mais velhas (acima de 25 anos) que precisavam ler e-mails, consultar algo na web, ou falar com alguém distante. Essas pessoas não passavam de transeuntes, e simplesmente "pipocavam" na lan, apareciam uma ou duas vezes (talvez, como eu, por conta do micro estragado em casa), e depois sumiam, sem deixar marca de sua presença. Entravam sem serem notados (se fosse uma bela mulher até notavam) e saíam assim também, não passavam de sombras que rendiam alguns tostões.

Entre as relações de um grupo mais unido é de se ressaltar que o bem de troca dos donos era "tempo de conexão". Não quero dizer com isso que não existiam relações desinteressadas, mas apenas salientar que "ser proprietário" da lan reservava um status muito especial para Léo e Tosco. A maioria sabia que era essencial estar de bem com os proprietários para ter livre acesso dentro da lan e, se possível, contar com a benevolência deles para ganhar alguns minutos de jogo, livres de pagamento. Os dois jovens vindos de fora do bairro integraram-se (e foram integrados) na rede de relacionamentos do bairro Passo do Ipê através da lan, conseguindo um lugar entre a hierarquia dos que já moravam ali, e fundaram uma lógica de funcionamento na lan que respeitava, acima de tudo, uma rede de amizades fundamentada no conhecimento tecnológico. Embora diversas pessoas transitassem ali, a lan era um local de jovens, onde a maior concentração era de pessoas maiores de 12 anos e menores de 22. A lan ingressou num contexto de "controle territorial" demarcado pelos jovens. Com isso quero salientar a importância do significado que os grupos

9 Sendo os apelidos a nominação por excelência dentro da lan é assim que me refiro aos jovens neste trabalho. As questões que envolvem a "escolha" do apelido auxiliam na compreensão do estabelecimento de fronteiras entre os grupos, onde uma identidade particular a partir de uma "denominação distintiva" (Strauss 1999) é criada, mantida, e só faz sentido dentro da rede de amizade que compartilha os mesmos códigos. 
e as redes de jovens davam aos lugares que freqüentavam no Passo do Ipê. ${ }^{10}$ A X-play dividia espaços com os points que eram usados para a sociabilidade, como a frente das escolas, as praças públicas, a quadra de futebol dos blocos, o shopping, entre outros. No entanto, a chegada da lan não se deu de forma harmoniosa, pois ela instaurava uma nova ordem e impunha a relocação de postos na hierarquia, se não uma nova hierarquia. É muito importante lembrar que se trata de pessoas de camadas populares, onde o acesso à tecnologia é restrito ou mesmo inexistente. "Ter o conhecimento da tecnologia" dava lugar de liderança frente a grupos onde outras habilidades eram mais valorizadas, como "ter conhecimento e bom relacionamento com os contraventores". Esses dois postos pareciam se debater, mas a diferença principal parecia mesmo estar no fato de uns serem "de fora" e estarem se estabelecendo num local onde já havia hierarquias, sem respeitá-las. Um estilo de "estabelecidos" e "outsiders" como apresentou Norbert Elias (2000) parecia ter se conformado por ali. Os estabelecidos eram os meninos do bairro, os que faziam parte do grupo "dos blocos", ${ }^{11}$ ou do grupo dos que conheciam os traficantes do bairro, e ainda dos grupos de escolas do bairro.

No início do negócio, Paulo contratou para trabalhar na lan um menino de nome Snake que morava no bairro há muito tempo. Por Snake ser bem relacionado, o espaço foi rapidamente adaptado ao cotidiano do bairro e, no período em que trabalhou por lá, não houve qualquer invasão ou roubo na lan. Posteriormente, quando Snake saiu do controle da lan e ela ficou a encargo de Tosco e Léo houve dois arrombamentos a pontapés da porta da lan (sem furto de material), um assalto, onde levaram duas CPUs (central de processamento do computador), e furtos de mouse durante o expediente.

Esses acontecimentos chamaram-me a atenção para a formação das redes e agrupamentos locais. Os arrombamentos eram formas repreensivas dos agrupamentos locais demonstrarem sua insatisfação com a imposição de liderança em postos como o de controle da lan por pessoas de fora do bairro. De qualquer forma, a lan era um estabelecimento com sede própria, com uma sala alugada, ou seja, mesmo que tenha ganhado um significado simbólico dado pelos jovens, o que chamo de point, era um espaço físico sob a responsabilidade de alguém, não era a "frente do colégio" nem a "esquina" nem "a praça". Os arrombamentos e assaltos não fizeram Paulo desistir do negócio. Ele melhorou a segurança colocando mais uma grade e porta extra de vidro. A insistência

10 A gíria "tá na área" é muito utilizada, bem como as pichações para estabelecer a presença em um local determinado de acordo com fronteiras simbólicas elaboradas (e compartilhadas) pelos jovens que definem os contornos espaciais de um lugar.

11 "Os blocos", como são chamados pelos meninos da lan, são um agrupamento de prédios contidos num conjunto habitacional distante uma quadra da lan. São oito edifícios, cada um com dez andares e doze apartamentos por andar, o que é popularmente chamado de "pombal" em Porto Alegre, sendo chamados de "balança" no Rio de Janeiro (Velho 1973). 
de Paulo em permanecer com a loja obrigou os grupos de "estabelecidos" a encontrarem um espaço para a lan bem como para Léo e Tosco. O fato dos donos jovens da lan entrarem para a rede já numa posição que permitia controle de um point acabou reconfigurando as noções de pertencimento e status naquele local, bem como formando novas redes de amizades.

Consegui perceber os nuances dessas redes logo que me decidi a fazer o trabalho de campo neste local. E isso se deu ao final de Julho de 2005. Mas demorei a entender as conformações e os agrupamentos bem como as hierarquias estabelecidas fora da lan. No princípio foram as particularidades da lan que me sugeriam a oportunidade de um rico trabalho de campo: era um espaço inovador, onde ofereciam serviços de games online $e$ onde os jovens poderiam "criar amizades e formar clãs". ${ }^{2}$ Entender essa nova forma de sociabilidade e conformação das redes sociais no espaço urbano por intermédio das novas tecnologias respeitava uma temática que há muito eu vinha trabalhando, o que me permitiu privilegiar a X-play Lan House como campo profícuo para a pesquisa de doutoramento.

\section{PRIMEIROS PASSOS DA ANTROPÓLOGA NA LAN HOUSE}

Minha primeira aproximação visou uma conversa despretensiosa; eu entrava na lan, usava um pouco o computador e depois puxava assunto. Quando esclareci para Léo sobre minhas intenções de pesquisa no local ele foi muito receptivo. Disse-lhe que me interessaria por alguns dados que talvez ele tivesse no servidor, como o tempo de conexão dos jovens e os programas mais usados por eles. Amistosamente ele mostrou a lista de programas mais usados. Em primeiro lugar estava MSN ${ }^{13}$ e Orkut, ${ }^{14}$ seguidos pelos jogos: Counter Strike ${ }^{15}$ e Tibia. ${ }^{16}$

12 Retirado de um folder da X-play elaborado pelos proprietários.

13 O MSN Messenger é um programa da empresa Microsoft dedicado ao envio de mensagens instantâneas a contatos adicionados numa lista privada. As conversas do MSN são travadas em pequenos quadradinhos (janelas) que ocupam parte da tela. Podem ser abertas tantas conversas (janelas) quantas o usuário tiver habilidade de manter.

14 O Orkut é um site de relacionamento que carrega o nome de seu criador, um funcionário da Google chamado Orkut Büyükkökten. Foi lançado em Janeiro de 2004 com a intenção de facilitar o encontro entre amigos. A página possibilita que se crie um perfil e adicione amigos à sua rede pessoal, de forma a aumentá-la cada vez mais. Também existe a possibilidade de se filiar a comunidades dos mais variados gêneros, criadas pelos próprios usuários do serviço. A maioria dos usuários são brasileiros, liderando com $60 \%$, contra $14 \%$ de americanos, $10 \%$ de indianos e $2 \%$ de paquistaneses, dentre outros (dados de 2006).

15 Counter-Strike (Valve Corporation) é um game de tiro em primeira pessoa, jogado on ou offline. Geralmente criam-se agrupamentos ("clãs") que se enfrentam e elaboram estratégias de ataque. Conhecido popularmente como "CS".

16 Tibia é um game de aventura da empresa alemã Cipsoft (1997), jogado em conjunto por muitos usuários na Internet, que desempenham papéis fantásticos de guerreiros, feiticeiros, paladinos ou druidas num mundo medieval. É grátis por tempo indeterminado, porém há a possibilidade de [continua] 
Alguns desses programas podiam ser usados em conjunto. E era isso que eu percebia quando passava por trás dos monitores esticando o pescoço para ver o que estavam fazendo. O mais comum era que a pessoa estivesse jogando ou Counter Strike (CS) ou Tibia e junto olhando o Orkut e com o MSN aberto. Nunca jogavam dois jogos conjuntamente.

No início do trabalho de campo eu levava comigo um bloco onde escrevia meus diários; ali anotava, em forma de rascunho, o que depois transformava numa anotação mais formal e com maior número de detalhes neste mesmo bloco. Quando comecei a ter mais intimidade com eles o bloco se tornou motivo de curiosidade; primeiro perguntaram o que eu anotava, então eu abria o caderno e mostrava alguns rabiscos sobre o número de máquinas utilizadas no dia, a hora que havia chegado na lan, quem estava jogando, o que jogava. As anotações tornaram-se mais ricas quando a familiaridade entre eu e eles aumentou e passei a descrever outras particularidades, como as características de cada um deles, bem como minhas impressões de alguns acontecimentos. Tive medo de permanecer com o mesmo bloco no campo, pois os jovens que eram mais presentes na lan já estavam criando um vínculo de amizade suficiente, capaz de permitir que pegassem o bloco para dar uma "olhada despretensiosa".

Os que freqüentavam com assiduidade a lan (isso significava ficar mais de 4 horas por semana dentro da lan house, jogando ou não) eram os aficionados pelo game Tibia.

Tibia é um jogo de aventura do gênero MMORPG (massive multiplayer online $R P G)$. Como a explicação do que vem a ser o jogo descende de uma sigla, sigo o esclarecimento prévio desta: RPG (role playing games) são jogos de interpretação de papéis. Surgiu em 1974 nos Estados Unidos e foi popularizado na década de oitenta. Tabelas e dados são indispensáveis para o jogo, mas o componente mais importante é, sem dúvida, a imaginação das aventuras criadas e vividas por todos. As aventuras são preparadas por uma pessoa que é conhecida como "mestre", que conduz e define os destinos em concordância com regras básicas ditadas por livros de apoio. As temáticas do jogo giram em torno de aventuras medievais, mitológicas, ficção-científica e terror.

Com o desenvolvimento dos computadores pessoais e da rede de informações Internet, os jogos de RPG transferiram-se para essa nova modalidade digital. Os dados foram substituídos por programações computacionais que passaram a controlar as pontuações. Os primeiros RPG online que surgiram (meados de 1980) foram denominados "MUDs" (multi user dungeon/dimension) e

pagar e conseguir vantagens extras com uma Premium Account. Tem uma configuração bastante modesta, não necessitando nem de um computador muito moderno nem de uma conexão com Internet de qualidade superior para seu funcionamento. Embora apresente grande número de detalhes, é um game em 2D (sem perspectiva). 
não faziam uso de gráficos e imagens, funcionavam somente de forma narrativa, totalmente textual (Fortim 2006).

O Tibia já é fruto de uma tecnologia que viabiliza o uso de imagens coloridas e em movimento, com ampla quantidade de detalhamento, mesmo que seja em 2D (sem perspectiva). Foi criado por três estudantes alemães da ciência da computação em 1997 que o reformularam constantemente e fizeram dele propriedade de uma empresa de jogos digitais que abriram, chamada Cipsoft. Trata-se de um jogo em terceira pessoa, ou seja, enxerga-se o personagem, representado por um "bonequinho", chamado de "char" (abreviação do inglês character), que caminha pela tela. $\mathrm{O}$ fato de não ter som torna-o mais leve, exigindo uma composição de computador relativamente modesta, funciona satisfatoriamente com uma conexão de baixa qualidade à Internet (embora, quanto melhor o computador e a conexão mais garantido é o desempenho do programa). O jogo é todo "esquadrinhado", ou seja, tem sua matriz baseada em quadradinhos que juntos compõem imagens de gramados, selvas, desertos, ou oceanos. Os jogadores dominam bem esse conceito gráfico, e várias vezes fui advertida porque não estava "clicando no quadradinho certo para subir a escada", ou para "pegar um item". As imagens visuais geralmente representam florestas e cidades com comércio e casas no estilo medieval. Não há um objetivo a ser alcançado para finalizar o jogo. A dinâmica do game envolve matar monstros, conquistar riquezas e aumentar seu nível (level) de experiência e habilidades do personagem de acordo com a vocação escolhida pelo jogador (guerreiro, druida, feiticeiro ou paladinho).

Madruga (20 anos), que jogava mais de quatro horas por semana na lan, era a exceção entre todos os outros freqüentadores assíduos, porque não jogava (atualmente, pois já havia jogado) Tibia. Ele preferia outros games, também estilo MMORPG, porém em 3D. Tosco e Léo, que também estavam constantemente na lan (por serem os donos) não jogavam Tibia.

As atividades que levam os jovens à lan podem ser entendidas a partir do seguinte quadro meramente ilustrativo.

Considero este quadro ilustrativo, porque estar em uma coluna não impede que o jovem faça atividades que estão em outra. Por exemplo, todos aqueles que vão à lan e jogam games, também se sociabilizam e usam Orkut e MSN. Todas essas pessoas têm em comum o fato de serem jovens, morarem próximos da lan e terem alguma familiaridade com a tecnologia. Porém, existem diferenças, principalmente entre os que jogavam e os que não jogavam. Quando me refiro a "jogadores ativos da lan" ou "freqüentadores mais assíduos" estou, propriamente, falando dos jovens presentes nas três primeiras colunas, que embora possam ter muitas incompatibilidades, foram observados em perfeita sintonia "jogando (ou olhando jogar) na lan": eles gritam, eles entram e saem, eles se xingam, "folgam" (zombam), eles grudam nas telas, eles discutem sobre os jogos incessantemente, eles estão com suas roupas largadas, tênis, bonés, eles falam 


\begin{tabular}{|c|c|c|c|}
\hline $\begin{array}{l}\text { Vão na lan, } \\
\text { jogam Tibia } \\
\text { e outros games }\end{array}$ & $\begin{array}{l}\text { Vão na lan, } \\
\text { jogam, } \\
\text { mas não Tibia }\end{array}$ & $\begin{array}{l}\text { Vão na lan para } \\
\text { sociabilidade, } \\
\text { jogam Tibia } \\
\text { em casa }\end{array}$ & $\begin{array}{l}\text { Vão na lan e não jogam, } \\
\text { (usam Internet - Orkut } \\
\text { e MSN e conversam na } \\
\text { porta) }\end{array}$ \\
\hline $\begin{array}{l}\text { Gaúcho (16), } \\
\text { Guiga (13), } \\
\text { Dabota (17), } \\
\text { Latininho (15), } \\
\text { Mentira (19), } \\
\text { Chuck (16), } \\
\text { Culi (17), } \\
\text { Cyclops (16), } \\
\text { CCB (15) }\end{array}$ & $\begin{array}{l}\text { Madruga (20), } \\
\text { Tatá (17), } \\
\text { Crazy (18), } \\
\text { Lalau (17), } \\
\text { Tosco (17), } \\
\text { Derik (17), } \\
\text { Bia (17), } \\
\text { e outros. }\end{array}$ & $\begin{array}{l}\text { Shwasnega (17), } \\
\text { Surfhoots (18), } \\
\text { Seninha (12), } \\
\text { Slayer (16) }\end{array}$ & $\begin{array}{l}\text { Leitão (16), Japa (17), } \\
\text { Zé Louco (18), } \\
\text { Silêncio (17), Mano (15), } \\
\text { Trasgo (18), } \\
\text { Dark Angel (17) } \\
\text { Maiumi (17), Jéssica (14), } \\
\text { Jaque (17), Aline (17), } \\
\text { Line (16), Léo (24), } \\
\text { e outros. }\end{array}$ \\
\hline
\end{tabular}

com gírias, eles bebem Coca-Cola, e comem salgadinhos de pacote e bolachas recheadas. Podem ficar de oito a dezesseis horas conectados sem sinais de cansaço. Sentem-se os donos da lan. Enquanto os "outros" não passam de "meros conhecidos", os jogadores fazem da lan uma espécie de "house" particular. O jogo é aí o elemento concentrador do grupo. Quem compartilha o "campo de batalha" nos games estabelece um laço diferenciado. O grupo de jogadores de Tibia é ainda um pouco mais coeso, são jovens de camadas populares, estudam no mesmo colégio (público), curtem o mesmo som (pagode, funk, hip-hop), usam as mesmas roupas (estilo esportista/surfista/hip-hop), anseiam por ter roupas de marca e acessórios digitais (MP3, celular, câmeras fotográficas), embora poucos o tenham. O item de maior desejo era, sem dúvida, um computador (ligado a Internet de boa qualidade), utensílio que a maioria dos usuários pesquisados não possuía, e quando o tinha, deixava muito a desejar, eram PC's velhos e com acesso a Internet de baixa qualidade (quando não os dois juntos). Os jovens, em sua maioria, não trabalhavam. Os empregos dos pais eram os mais diversos: bancário, mecânico, servente, manicure, militar, cozinheira, funcionário público, aposentados e autônomos. Conseguir algum dinheiro não parecia fácil para esses jovens aficionados em promover seus personagens nos games online.

\section{USANDO CÓDIGOS NO DIÁRIO DE CAMPO, ESTRATÉGIAS DE UMA PESQUISADORA NA CIDADE}

Diante de tantas particularidades, ficou claro que eu não poderia deixar de anotar durante o trabalho de campo, até porque aquela miríade de armamentos, monstros e outros nomes do Tibia eram bem difíceis de decorar. Houve momentos em que passei mais de oito horas na companhia deles, e seria árduo lembrar os acontecimentos, fatos e dizeres sem ter, ao menos, anotações de 
base. Vendo a impossibilidade de continuar com o bloco foi necessário pensar outra estratégia para anotações. Por isso adquiri uma caderneta bem pequenina $(15 \mathrm{~cm} \times 10 \mathrm{~cm})$, na qual passei a fazer descrições as mais diversas. Mesmo assim, sentia falta de escrever com maior liberdade sem sofrer nenhuma represália se viessem a ler o que estava escrito. Sempre lembrava que esse problema era relacionado somente a pesquisas antropológicas onde os interlocutores soubessem ler. Por isso não encontrava nenhuma indicação referente a esse problema nos estudos clássicos antropológicos que trabalharam com sociedades que não privilegiavam a escrita.

Mesmo fazendo apontamentos superficiais que seriam aprofundados em casa, a suposição de que pudessem pegar a caderneta causava uma certa apreensão de minha parte e controle na escrita, restringindo anotações das minhas impressões de campo. Numa situação, onde houve acusações verbais e um clima de tensão na lan a respeito de um acontecimento no Tibia, vi que era preciso anotar. Saquei caneta e caderneta da bolsa, estava pronta para fazer algumas referências quando... felizmente lembrei-me de um código criado na sétima série do ensino básico... saí escrevendo milhares de "tracinhos, quadradinhos e riscos tortos" com muita habilidade. Sinais muito claros para mim mas inviáveis para quem porventura pegasse a caderneta para "dar uma olhada". A idéia de usar o código deixou-me à vontade para descrever as mais diversas situações, como: favorecimentos, brigas, ameaças, constrangimentos, discriminações, vendas ilícitas, namoros, drogas, privilégios, disputa de poder e prestígio, proteções, dentre outras. Colocando em prática esta artimanha, podia deixar minha caderneta por cima das CPUs, mesas ou monitores sem me preocupar se iriam pegá-la ou não. De fato pegaram-na muitas vezes, e logo que um deles viu que eu escrevia em códigos, perguntou-me do que se tratava, e eu rapidamente respondia (em tom de brincadeira) que estava em código, e se estava em código era para não saberem. Dabota disse uma vez: "a Vicka escreve em chinês". Também faziam anotações, rascunhavam o nome, faziam desenhos, pichavam, ou deixavam recados quando abriam a caderneta. Por vezes, escreviam como se fossem eu, expressando um desejo ou um acontecimento: "esta tarde estou com muita sede e vou comprar um refri 2 litros" (caderneta, 04.05.2006, escrito por Mentira), "Estou em level 40 as 17:00 estou em party com o lalau o culi vai entrar com o outro personagem dele pra nos fazer party e matar uns bixos mais forte (...) fico apavorada quando estou quase morrendo =] By Dabota-Lindu" [sic] (caderneta, 06.06.2006, escrito por Dabota).

Estar com uma caderneta, por menor que fosse, dentro daquele espaço era algo realmente estranho e aguçava a curiosidade. Por isso a opção de usar códigos foi uma saída interessante que me permitia compartilhar um pouco do meu trabalho com eles sem deixar de fazer minhas próprias anotações pessoais, e sem o medo de correr o risco de causar constrangimentos nos relacionamentos nem revelar segredos que havia descoberto. 
Mesmo que eu andasse sempre com minha bolsa, onde ficava guardada a caderneta, atravessada no corpo o tempo todo, na maioria dos momentos era inviável sacá-la para fazer anotações. Quando eu estava jogando, concentrada, e tentando perceber ao mesmo tempo o que passava na volta (com o tempo desenvolvi razoavelmente bem essa habilidade), deixava a caderneta aberta e a caneta pronta para qualquer anotação. Nas conversas informais do sofá da recepção também era possível anotar e mesmo quando me sentava junto a alguém que estava jogando. Mas como alguns dados mais particulares da vida deles eram conseguidos na sua maioria, somente em "passeios" pela rua, era impossível caminhar e anotar. Ou quando estávamos todos reunidos conversando, trocando idéias e "folgando" também era impróprio ficar anotando. Reconheço que posso ter perdido um pouco da linguagem (algo tão singular) porque não era possível reproduzir em casa, no diário, exatamente o modo como tinham se expressado. Um gravador seria de grande ajuda, mas o gravador foi rechaçado. Embora o aparelho tivesse pequenas dimensões $(15 \mathrm{~cm} \mathrm{x}$ $6 \mathrm{~cm}$ ) criava um constrangimento total entre eles. Não fiz nenhuma gravação sem consentimento, e consentida só foi possível com Dabota, um momento que me ensinava RYL ("risk your life", um game em 3D da Planetwide Games); e com Léo relatando-me sobre RPG de mesa. Era necessária uma distância mínima entre a boca do falante e o gravador e, por mais que estivessem familiarizados com novas tecnologias, o gravador era inaceitável, como demonstrou Culi: "isso não tá ligado, né?", "não liga, senão, não vou falar".

Envolvida num ambiente de alta tecnologia fui obrigada a coletar dados do modo mais tradicional: escrita. É bem verdade que houve uma boa aceitação da máquina fotográfica, um recurso que permitia perceber muitas sutilezas das relações entre eles, como no dia em que tirei foto do "clã de CS" do qual participavam: Mentira, Derik, Bia, X, Tosco, Léo”, foto que eles mesmos pediram para eu bater nas escadas de entrada da lan e onde aparecem abraçados no degrau de baixo: X, Bia, Mentira e Derick, enquanto Tosco e Léo estão atrás, no degrau mais alto sem encostar nos amigos. Certa vez questionei Mentira porque Chuck não participava do clã, afinal, pelo que eu tinha observado, ele jogava melhor do que Tosco, ao que Mentira respondeu: "Vicka, o Chuck tem lan?". A foto era clara, mostrava os laços de amizade e ainda desenhava uma pirâmide onde no alto estavam os "donos da lan".

Também posavam para fotos que depois pediam para colocar no álbum de fotos do Orkut. A maioria das poses era feita imitando cantores de hip-hop, o que me ajudou perceber a influência musical, não só sobre a vestimenta, mas nas disposições corporais e modos de se cumprimentarem. ${ }^{17}$

17 A pesquisadora Sandra Regina Soares da Costa aponta que a moda hip-hopper vai além dos salóes de bailes ou boates, tornando-se hoje "um dos principais signos de uma cultura jovem e urbana" (2002: 40). 
Até agora, especifiquei que os dados de campo foram conseguidos através da escrita no diário, auxiliado por uma caderneta, pouca coisa com gravador e algumas imagens, mas utilizo também dados digitais, através do Orkut e do MSN e mesmo através do chat interno do jogo do Tibia. Tenho gravadas muitas conversas via MSN. Este programa foi de grande auxílio, porque me permitiu manter contato com muitos deles quando não estava dentro da lan. No início da pesquisa pensei em fazer algumas entrevistas por MSN, mas todos falavam no máximo vinte minutos e saíam quando as perguntas não eram sobre games. Invalidei essa opção no dia que descobri ter sido bloqueada por Chuck por estar incomodando-o com perguntas demais. O MSN era comum a todos na lan, aos que jogavam, aos que jogavam em casa, aos que ficavam na porta, às meninas. E quem tinha MSN tinha Orkut. O Orkut era publicizado, não público, porque tudo que estava aparecendo era porque o proprietário da conta permitia. Nesse programa, a parte relativa aos scraps ${ }^{18}$ e adesões a comunidades, as quais observei, dava indícios das relações de afinidade e da construção das redes sociais de cada um.

Através dos bate-papos ao vivo (encontros pelo bairro em geral), dos encontros na lan (ver e ser vista) e de estar ligada também na Internet através de MSN e Orkut eu passei a me sentir mais à vontade entre eles. O fato de conhecer Léo e estabelecer com ele (o dono) uma relação de amizade foi essencial, porque agora, embora nem todos soubessem o que eu fazia lá, ao menos Léo sabia e, assim, tinha o "trânsito livre". Mas o que significava de fato "estar no grupo" eu só vim a saber com mais tempo de relacionamento, porque implicava estar envolvida ou ao menos compreender uma "rede de relações" que incluía games, mas também laços para além da lan (que envolviam parentesco, amizades de infância, vizinhança, ou mero conhecimento do status dos indivíduos e suas relações). Como eu vinha de "fora desta rede", foi preciso "estar na lan freqüentemente" para tentar captar esses laços; isso significava aparecer todos os dias da semana, e ficar mais de três horas dentro da lan. Esse foi um tempo mínimo para começar a perceber o fluxo de trânsito dentro da lan, e quais os assuntos de maior importância para os jovens. Também observei a enorme quantidade de tempo que era gasto nos games. Se eu ficava três horas dentro da lan, havia sempre alguém que estava jogando quando eu chegava e continuava quando eu saía. Eles passaram a me conhecer pelo nome, digo, pelo nome que me apresentei depois que percebi que os apelidos eram essenciais: "Vicka". Meus primeiros contatos foram através de bate-papos em agrupamentos que sempre se formavam em volta do balcão de atendimento. As meninas eram poucas: Aline, namorada de Lalau e Maiumi eram as que mais apareciam para conversar. Nunca vi Aline usando um computador, e Maiumi, quando precisava usar, pedia carinhosamente permissão a Léo, para acessar o servidor do balcão de atendimento. 
Eu nunca cheguei a me sentir muito "estranha" dentro da lan, primeiro porque era um lugar público, segundo porque achava que não tinha um estereótipo tão diferenciado (embora tenha descoberto muito sobre meu próprio senso de juventude) e, terceiro, porque agora eu era alguém com um lugar: amiga do Léo que estava fazendo uma pesquisa. Era isso que ele dizia para os amigos que ia me apresentando. Neste momento achei muito convincente usar a explicação de W. Foote Whyte (2005) quando estudou imigrantes italianos moradores de um bairro pobre de uma cidade nos Estados Unidos: estava escrevendo um livro. E assim falei: "estou escrevendo um livro sobre jovens e lan house". Eles não ficavam muito satisfeitos, ao contrário dos imigrantes de Foote Whyte, perguntavam porque a lan house e o que conteria no livro. Mas quando eu começava a explicar alguma coisa mais complexa e demorada, qualquer chegada de amigo fazia-os distraírem-se. De modo que nunca mais voltavam a me perguntar. Sabiam que pesquisava algo, não sabiam exatamente o quê. Com uma diferença de dez a quinze anos é inegável que minha presença fosse diferenciada entre eles. Eu me vestia de modo parecido com as meninas que freqüentavam o local, usava roupas justas esportivas, sempre de tênis nos pés. Mas eu não era "jovem" como eles, destoava. Certa vez um casal entrou na lan e notou o balcão de atendimento vazio. Foram adentrando na loja, dando pequenos passos. Eu estava de pé olhando o monitor de alguém que jogava. Eles olharam todos aqueles jovens e dirigiram a palavra para mim, perguntaram-me qual o preço por hora e se poderiam usar uma máquina. Concluíram que, se alguém entre todos aqueles gerenciava o negócio, esse alguém só poderia ser eu! Léo viu que entraram pessoas, mas estava distraído demais ajudando um amigo num micro no fundo da loja. O casal foi atendido logo depois que chamei a atenção de Léo apontando os clientes. Porém, somente após ele ter explicado o detalhe do jogo para o amigo. Na maioria das vezes, as coisas tinham essa ordem na lan: dava-se prioridade para o amigo ao invés do negócio.

Mesmo que me vestisse de forma parecida, tivesse assumido hábitos alimentares iguais aos deles (comi muita bolacha recheada, salgadinhos de pacote, refrigerante, balas, chicletes, rapadura), tivesse aprendido a falar como eles (com uma entonação toda especial nas frases e uso de gírias como "tá ligado?", "bala", 19 "noob", ${ }^{20}$ "tá loco") eu era uma mulher de 30 anos metida no meio de jovens de 17. Se eu estivesse usando o computador em silêncio, ninguém notava minha presença, afinal o local era público e próprio para usar a Internet, mas quando entravam pessoas acima de 25 anos e me viam aos gritos,

19 "Bala": gíria que significa algo que é "legal", designado a pessoas ou coisas qualificando-as com atributos positivos.

20 "Noob" é o novato no game, qualifica alguém que faz uma ação errada, ou que não apresenta habilidade no Tibia. 
jogando games, estourando bolas de chicletes, brigando por um copo de refrigerante, e sendo achincalhada pelos jovens, eu era capaz de sentir os olhares de estranhamento que caiam sobre mim. Esses olhares (desconfiados) vinham até mesmo de outros jovens não integrados ao grupo. Gênero e faixa etária eram as diferenças visíveis a qualquer um, principalmente porque nenhuma das meninas jogava. Bia, uma bela jovem de 17 anos e cabelos cacheados cor de mel, chegou a ficar um mês indo a lan todos os dias, impulsionada por dois motivos que saltavam aos olhos de qualquer um, os quais eu não saberia a ordem de precedência: participava do clã de CS, e estava interessada em um dos meninos que ia diariamente na lan. De fato Bia foi a única menina que vi jogar durante todo esse tempo. Jogava muito bem CS (de acordo com os comentários gerais), mas não jogava Tibia.

Logo que comecei o trabalho de campo imaginei que algumas daquelas meninas que ficavam pelos degraus de entrada da lan jogassem. Engano meu. Elas no máximo olhavam o Orkut e o MSN. Jéssica certa vez me disse ter "horror" do Tibia porque seu namorado dava mais atenção ao jogo do que a ela. Elas conheciam o nome do game, o seu visual, mas não achavam "graça naquele bonequinho andando, andando. Prefiro ficar fofocando no MSN." (Jaque). Logo ficou claro que a lan e seus games eram um ambiente marcadamente masculino.

\section{DESCOBRINDO O MUNDO FASCINANTE DE TIBIA}

Portanto, ser mulher e mais velha já eram características que me distanciavam muito deles, era necessário escolher uma que pudesse me integrar, foi então que percebi a grande potencialidade do Tibia. Logo no terceiro mês de trabalho de campo (Outubro/2005) decidi jogar Tibia na tentativa de ficar mais próxima dos meninos. Não era uma versão oficial do jogo e sim o OT (open Tibia server), um jogo que imita o Tibia original, porém é instalado num servidor ${ }^{21}$ particular. As regras são modificadas nesta versão de forma que se pode aumentar de nível e conseguir itens valiosos muito mais facilmente. Eu não me interessava exatamente pelo jogo, queria apenas me inserir no grupo de jovens. Como minha experiência com jogos digitais sempre foi muito restrita, cheguei a cogitar a possibilidade de estudá-los apenas observando-os jogar. O público na volta nunca os incomodou, aliás gostavam que ficassem olhando sua performance. Mas em Março de 2006, quando retomei os estudos e ouvi o primeiro bate-papo no que chamei de "tibiês" (a linguagem do Tibia), percebi que não teria a menor chance de entender o que se passava sem jogar. Aliás não poderia

21 O Tibia é um programa de computador que funciona no modelo "cliente-servidor"; o computador "servidor" contém e grava todas as informações do game, e é acessado por um "cliente", que é um programa que pode ser baixado e instalado em qualquer computador, transformando-o em um terminal de acesso ao servidor. 
continuar no Tibia OT, que era, como dizem, um "mundo de brincadeira" e não o "de verdade". Isso porque o OT sempre era instalado num servidor que poderia ser apagado facilmente e, então, todo o esforço de manutenção do personagem era perdido, não havia nenhum comprometimento daqueles que mantinham o servidor com os jogadores. Já o Tibia original roda num servidor alemão da empresa CipSoft (com sede em Regensburg). Nunca foi apagado, apenas reformulado, sendo que os personagens nunca se perderam. A maior parte das discussões em "tibiês" eram referentes a esse Tibia oficial, chamado de Tibia Global.

Considero válida a experiência que tive no Tibia OT, aprendi a usar o mouse e o teclado para dar movimento ao "bonequinho", bem como a reconhecer toda estética do game. Joguei OT até Dezembro quando a X-play mudou-se para litoral a fim de tirar um lucro maior com temporada de veraneio gaúcha (meses de Janeiro e Fevereiro). A loja da lan, na Rua Conde Isidoro, permaneceu fechada até o mês de Março, quando retornaram e reabriram o negócio.

Descrevo a seguir o diário de Março de 2006, quando retomei o trabalho de campo.

Escolhi relatar essa parte porque consta a minha ignorância frente ao jogo Tibia, e como discutem a respeito dele, porém exponho grande parte do diário porque dá um panorama geral da dinâmica do cotidiano da lan:

Quando a lan retornou da praia, Leonardo comunicou-se comigo pelo MSN, perguntou quando eu iria aparecer, disse estar com saudade. Eu, por certo, também estava. Eles ficaram dois meses com a lan instalada numa praia gaúcha chamada Capão da Canoa.

Infelizmente não consegui visitá-los.

Saí de casa para fazer minha primeira visita do ano na lan.

Quando entrei, Marcos estava de pé, Léo sentado atrás do balcão. E Dabota sentado no sofá, este nem se levantou para me cumprimentar com beijinhos. Marcos foi carinhoso e Léo saiu de trás da mesa e me deu um forte abraço.

Comentaram que Culi estava dentro da lan, lá no fundo. A lan parecia maior, agora que o número de PC's havia dobrado (agora são 22, eram 11). Fui até o fundo onde estava Culi concentrado na tela brilhante, jogando Tibia. Do seu lado estava um menino loirinho de idade inferior a dele, provavelmente com 12 anos [Guiga]. Culi estava de cabelo bem curtinho, estilo raspado. Eu dei "oi", comentei que em Outubro do ano passado ele havia dito que "largaria o Tibia de mão", no entanto... Ele ficou sem jeito, ou era mesmo o jeito quieto dele, dá um sorriso, e continua olhando pra tela, como se não pudesse desgrudar os olhos dali.

Antes dos pais do Léo chegarem estávamos numa conversa informal no sofá: Chuck, o loirinho de 12 anos, um moreno de cabelos compridos [Surfhoots], eu, um outro menino de 17 anos, Dabota e Tosco. Por alguns 
instantes ficaram falando de itens do Tibia, sobre itens que um daria, ou venderia ao outro, armamentos, poções, escudos. Mas isso foi o que "pesquei" por alto, pois a impressão que tive foi que estavam falando outra língua, eu realmente não entendi, fiquei surpresa! Devo aprender mais Tibia? E se eu jogasse um pouco? Ainda não resolvi.

Depois de falar do jogo, ficaram numa conversa informal, no que eu chamaria de "discussão de meninos", isso inclui "folgar", contar vantagens, xingar com palavrões, estabelecer diferenças, buscar afirmação. Mas devo expressar isto de modo mais claro em outro momento já que faz parte constante dos bate-papos dentro da lan. Estavam todos muito despojados, o menino de 17 anos ocupava todo o sofá de dois lugares, estava deitado nele com as pernas em cima dos braços do estofado, os outros escorados nas paredes ou sentados nas cadeiras de computador que foram puxadas para próximo do sofá, formando uma "informal" salinha de conversação. Quando chegaram, a mãe (Marta), e o pai (Paulo) de Tosco, a mãe já foi dizendo pro menino que sentasse direito!

Paulo ficou no balcão e Marta foi até a pecinha dos fundos da lan, (um espaço de $6 \mathrm{~m}$ x $6 \mathrm{~m}$ que tem camas, mesa, fogão e geladeira). Fui falar com Marta, minha intenção era comentar com ela sobre meu trabalho.

Iniciei falando de minha idéia de intensificar a presença neste local, que eu era estudante, que meu estudo exigia ficar constantemente presente entre os jovens, observando suas atitudes, suas predileções, seus jogos. Ela se mostrou muito receptiva.

Quando retornei para o centro da loja, observei que o grupo que conversava animadamente tinha se desfeito completamente. Só havia um garoto usando o micro. A presença de Paulo e Marta certamente melindra os meninos.

(Nota de 20 de Março de 2006)

Eu queria me aproximar justamente do grupo que saiu da lan com a presença de Paulo e Marta. Por isso resolvi que deveria jogar o Tibia oficial. Cadastrei-me no site do game a fim de começar a entender o "tibiês":

Segui todos os passos necessários no site (em inglês). Meia hora depois obtive um número de conta.

O Tibia era o jogo mais jogado pelo público regular da lan. Todos tinham char, a maioria, mais do que um. Desde o início da pesquisa eles jogavam este jogo. Esperei para ver se não era algo como uma febre passageira mas, quando retornei em Março, muitos continuavam jogando. Não deixavam de jogar outros jogos, como foi o caso do RYL, porém, logo que exploravam as mais altas possibilidades do game todos paravam de jogar juntos e voltavam sempre ao Tibia. Assim fizeram também com Battlefield (EA Games), um game de guerra, onde o objetivo é conquistar bandeiras inimigas. Aprendi todos esses jogos, inclusive o CS que, segundo eles, era um dos games mais famosos em lan 
houses. Todos os que jogavam Tibia regularmente sabiam jogar CS, mas eles não davam a esse game a importância que davam ao Tibia. O maior diferencial do Tibia talvez fosse o acesso a todas vantagens de um mundo "real" e não de servidor "pirata" (como chamam os servidores não oficiais), de disputas com iguais, sendo que era totalmente grátis. Havia diversos mundos, lindos, mágicos e muito mais perfeitos que o Tibia, mas os jovens da lan X-play não tinham dinheiro, ou não tinham motivação (rede de amizade) ou não tinham cartão de crédito (meio para alcançá-lo). O jogo não era somente o motivo principal de ir à lan, como era fonte de inúmeras discussões acaloradas, angústias, entusiasmo, projetos e estreitamento de laços da rede de amigos.

Para o meu processo de entrada no campo, o Tibia foi essencial. Embora este game seja "tosco" como alguns falam, "com um gráfico horrível" (porque é em 2D), até mesmo "um lixo", era, inegavelmente, o mais jogado. Essa insatisfação de uns com o jogo era equilibrada pelo posicionamento positivo de outros tantos que jogavam diariamente e diziam que "o Tibia é o melhor", "Tibia é bala", "a jogabilidade do Tibia é perfeita".

Criei (com total ajuda dos meninos) um char, chamado: “Tia'Vi”. Logo fui descobrindo que uma ajuda inicial era comum, meu boneco começou com armaduras, itens e dinheiro que não tinham sido mérito dele. E assim alguns indícios sobre a "proteção" do grupo começaram a aparecer. Depois que recebi os itens emprestados (principalmente a "espada katana") do Mentira passei a sentir-me comprometida com ele, sobretudo quando disse-me: "não perde esses itens e depois me devolve, eles são os melhores de Rookgard".

Rookgard é a ilha inicial do jogo, onde o char novato começa e fica até o nível 8, depois o char pode ir para "Main", o continente central do jogo. Main possui três cidades principais: Carlin, Thais e Verone. A passagem de Rookgaard para Main exige um "ritual de passagem" no qual o jogador vai até o Oráculo e escolhe uma vocação entre as quatro do Tibia: Druid, Paladin, Sorcerer, ou Knight. Depois da vocação o jogador deve escolher a cidade em Main que deseja ir e então será magicamente transportado para lá sem chance de retornar a Rookgaard. O mundo de Shanera, onde joguei, era um mundo considerado "PvP", ou seja, "player versus player", significa que os jogadores, além de matar os monstros do game, podem matar uns aos outros. Existem três tipos de mundo: "PvP", "PvP-enforced" (onde se estimula o ataque a outros personagens) e Non-PvP (onde não se pode matar o outro char). Estar num mundo PvP exige alguns cuidados e, como vim a entender, exige também "ter amigos fortes" que possam ajudar caso você tenha "algum problema com outro player".

A "honra" de qualquer jogador da lan tem sempre a proteção dos "amigos". Portanto não importam os jogadores de $l e v e l^{22}$ baixo, e sim quantos amigos level

22 O "level" é o melhor delimitador de um char. Demonstra o nível do personagem no game. Mesmo que possa ser contrastado/combinado com outras habilidades, o level (e eles sempre falam [continua] 
alto estão na "lista vip" (trata-se de uma lista de amigos como no MSN, que são adicionados dentro do Tibia). Em Setembro de 2006 a "Finky'Skardufax" (personagem de Dabota) estava level 60, isso significava que Tia'Vi (já com level 20 nesta época) podia seguir seu caminho tranqüila, com certo respaldo pois, se um char resolve atacar, assim explicou-me Dabota pelo MSN:

[Vicka] diz:

olha só. se um lvl [level] 30 me mata pra se divertir, o q acontece?

_DaBoTa_diz:

eu do hunted neli... faço eli paga tua morti

[Vicka] diz:

como vc faz isso? manda recado pra ele?

_DaBoTa_diz:

a naum ser se ele estiver largandu o server dae naum tem como fazer nada

[Vicka] diz:

é tipo uma perseguição?

_DaBoTa_diz:

$\mathrm{s}$ [sim]

_DaBoTa_diz:

por issu eh q hunted

DaBoTa_diz:

se ele naum paga eu vo atras deli e matu eli

(Conversa no MSN, 12/09/2006)

Há uma espécie de sanção grupal, o que inviabiliza os assassinatos ou ataques a personagens sem que não possam ser cobrados pelos seus atos.

Jogando Tibia fui me aproximando mais deles. E não bastava jogar (algo que eu poderia fazer em casa), e sim estar jogando na lan. Esse era o requisito mais importante para aproximação e reconhecimento como par. Eles davam extrema importância para a atividade do jogo, e todas outras tarefas cotidianas eram organizadas a fim de sobrar o tempo essencial necessário para "uppar" (do inglês "up" subir, também transformado em verbo corrente). Desse modo, descobri que há um controle coletivo sobre cada char, ${ }^{23}$ e sempre há uma suspeita a respeito das atividades "extras" que impediram o sujeito de aperfeiçoar seu char. Essas atividades "extras" eram quaisquer outras que não "jogar": ir ao colégio, fazer algum esporte, namorar, ajudar os pais, trabalhar. Assim fui

[continuação] em inglês, nunca se referem a "nível") dá status de poder no jogo. Logo que alguém fala que joga Tibia, a primeira pergunta é: que level?

23 No site oficial do game (www.tibia.com), ou no site brasileiro (www.tibiabr.com) é possível fazer uma pesquisa pelo nome do char e verificar o level, e outras características do jogador. Eles acessam constantemente esses dados para obter informações sobre sucessos ou infortúnios dos chars dos jogadores. 
descobrindo que através do desempenho do char eu poderia descobrir as outras atividades que esses jovens faziam e qual importância davam pra elas.

As suspeitas sobre quem eu era foram sumindo quando comecei a jogar sério. Jogar sério significava que eu deveria me preocupar em uppar, em matar, em melhorar skills (habilidades), em comprar equipamentos de qualidade, em entender as regras de convivência do Tibia, em aceitar dicas, e discutir posicionamentos diante de problemas acontecidos dentro e em função do jogo.

Mas voltando um pouco no tempo, quando finalmente Tia'Vi passou para Main (ou seja, estava level 8), anotei no diário:

Comentei com Mentira que tinha medo de morrer agora que era level 8 e sabia que os personagens podiam se matar, afinal "Shanera", o mundo em que eu estava, era PvP. Ele me explicou que isso não iria acontecer, se eu respeitasse as normas ninguém ia querer me matar por nada. Então... isso era dizer nada pra mim, porque eu não saiba as "normas"!

Uma delas, era que agora eu não poderia entrar numa caverna e sair matando os bichos dos outros, nem fariam isso comigo, como me explicou:

"se você estiver treinando ou lutando com bichos e chegar um char, você diz: não mata, please!, se o carinha atacar seus bichos aí você avisa pra um de nós que tiver online, e se um carinha te perseguir sem motivo, você também nos avisa. Você agora tem que sair e matar muito porque você é um knight (um guerreiro) e suas habilidades vão subir conforme você mata. Te dei uma arma melhor do que a katana, e mais um elmo, um escudo e uma armadura. Esses itens são bons e ajudam a matar mais rápido."

Eu não falava nada, escutava com atenção.

(Nota de 11 de Abril de 2006)

Essa nota ilustra também a sensação de "proteção" que passei a sentir no mundo do Tibia. Ao mesmo tempo em que ser jogada num "mundo desconhecido" era muito estranho, ter o "suporte" dos amigos era confortador. Pesquisadores dedicados a compreender a dinâmica social nos MMORPGs Ultima Online (Eletronic Arts) e Everquest (Sony Online Entertainment) apontam que a complementação de um personagem novo com itens, dinheiro e armamentos dos companheiros antigos é comum nestes games. A "fusão de alianças" através dessa prática de reciprocidade garante um potencial de competitividade e resistência contra as adversidades a que o jogador novo está submetido (Kolo e Baur 2004; Tosca 2002).

Mentira (mais do que Léo, que era o dono da lan, mas não jogava) facilitou minha integração com o resto do grupo. Além de toda ajuda particular com o game, ele sempre me cumprimentava muito amavelmente quando eu entrava na lan. Foi o primeiro a me dar apoio nas "folgações" (partidário de minhas colocações contra os outros), sempre direcionava o olhar para mim forçando 
os outros a fazerem o mesmo quando eu perguntava algo, sempre comentava sobre como estava o "Tia'Vi" com os outros que jogavam Tibia, e também "folgava" em mim.

Duas ações permitiram entender o quanto estava me integrando: o fato de jogar Tibia, e a "folgação".

\section{A FOLGAÇÃO}

"Folgar" era um termo que ouvia diariamente dentro da lan. Trata-se de ações de deboche, troça, que fazem constantemente uns com os outros. Mas só entre o grupo e para o grupo. Ninguém folga em alguém de 40 anos que entrou na lan para ver seus e-mails. Ninguém folga no desconhecido, a não ser entre os amigos, sem que a pessoa perceba. Essas brincadeiras verbais, que primam o riso e distanciam-se da seriedade, davam o tom a todos assuntos dentro da lan:

Sinto-me mais à vontade para perguntar coisas para o Guiga. Temos nos visto diariamente e ele sabe que estou estudando a lan. $\mathrm{Na}$ verdade, o fato de eu ter começado a jogar Tibia facilitou-me falar com eles, é como se agora eu participasse de um time, não sei bem explicar, me sinto à vontade, sei que estou sendo aceita.

Ontem nas brincadeiras dei dois cortes verbais no Chuck (o mais "língua-solta") e os meninos (Mentira, principalmente) ficaram do meu lado, debochando dele: "bá, Chuck... tomou queimão da Vicka".

Mas eles também têm se sentido mais à vontade para folgar em mim, me chamando de "velha" principalmente quando não entendo alguma coisa, aí dizem: "aqui ó tia, aqui ó", ou "entendeu véia?".

(Nota de 06 de Abril de 2006)

Guiga (13 anos) caçoa constantemente de todos, se não estiver logado num PC jogando (único momento de introspecção), está sempre procurando indícios que lhe permitam falar uma "bobagem" de alguém. A legitimação que lhe concedem através das risadas e comentários demonstra o quanto ele é bem sucedido com suas folgações. As risadas e "contra-folgações" (respostas) definem o grau e aceitação e posto na hierarquia, até mesmo inclusão ou exclusão no grupo. Guiga disse-me certa vez: "folgar é a coisa mais bala que inventaram, se conheço o cara folgo nele... e se não conheço... daí eu acho alguma coisa pra folgar". Logo que iniciei o trabalho de campo era difícil lidar com as folgações, primeiro porque eu achava que não deveria rir, para manter o respeito pelo outro. Mas incontáveis vezes não consegui conter meu riso, principalmente quando era Guiga fazendo as argumentações das zombarias. Depois percebi que poderia sim, e deveria rir e também aceitar as folgações bem como fazê-las pois, 
folgarno outro, era prova do conhecimento de sua vida, suas particularidades e privacidades. Quando passei a não controlar meu riso, percebi também que "entendia" a folgação, que havia desvendado intimidades de cada um.

Os limites entre o aceitável e inaceitável numa folgação variavam muito. Vi Guiga sair correndo da lan muitas vezes, por medo de apanhar de alguém em quem folgou, por ter ido "longe demais". Mas ele sempre saía rindo. Quando não conseguia sair e pegavam-no, ele rapidamente se redimia: "tá desculpa, meu, não vou falar mais, juro, juro!”. Juramento que durava segundos, dependendo da represália feita. A represália consistia basicamente no uso (ou ameaça de uso) da força física.

Para executar uma folgação com sucesso é necessário uma platéia ativa, capaz de compreender a folgação e dar o aval (com risadas!), e exige uma compreensão da vida pessoal dos amigos. Para tanto, era necessário prestar atenção ao que era comentado por cada um sobre sua vida privada, observar os "discursos" (histórias da vida) feitos e conhecer o modo de viver do amigo, essas eram informações base que serviam para folgação. A folgação pode ser feita também fundamentada nos aspectos físicos, situação econômica e familiar, motivações pessoais, romances, inabilidades, ou habilidades, e posturas diante dos acontecimentos.

Folgar não é fofocar. Não têm precisamente a intenção de definir e reafirmar normas de regulamentação de comportamento (Epstein 1969, Elias 2000). A folgação não imputa um valor moral, e não é feita "às escondidas", e sim junto do sujeito folgado e de preferência diante de outros. Ela conta e necessita dessa exposição pública, de preferência nunca entre duas pessoas. A folgação fica muito divertida e se torna motivo de união e permanência coletiva quando há um grupo grande. Foram em momentos como esses que eu conseguia descobrir detalhes da vida dos meninos fora da lan, e também sutilezas de seus relacionamentos na rede de amigos.

Neste sentido, folgar se parece muito com uma relação de "jocosidade" (joking relationship) como as relatadas por Radcliffe-Brown (1973) e Mitchell (1971). Mesmo estudando relações diferenciadas, Radcliffe-Brown estudando parentesco e Mitchell estudando relações tribais africanas num contexto de ocupação da colonização inglesa, os dois autores pontuam que as relações de jocosidade criam uma aliança entre os clãs, tribos ou parentes através desse comportamento que permite manter uma estabilidade no sistema social. Ambos estudiosos mostram o caráter público dessas relações, exigindo a participação de uma platéia que domine os códigos em jogo. Apontam também a prática de união e cooperação que essas relações permitem estabelecer.

Conseguir esse grau de intimidade, que permitia as brincadeiras de folgação, foi algo que só obtive a partir da integração no game Tibia. Partilhar com eles o game foi indispensável para entender as conformações das redes de relações e os significados que davam para elas. 


\section{CONSIDERAÇÕES FINAIS}

Essa pesquisa de campo com jovens brasileiros na X-play Lan House de Porto Alegre ainda está em curso. Iniciei o trabalho a partir de uma relação de estranhamento de algo que parecia muito próximo, o que caracteriza o desafio dos pesquisadores urbanos (Velho 1978) e os coloca sempre em "estado de alerta".

A natureza complexa e diversificada da vida na metrópole torna-se terreno fértil para inauguração de espaços sociais diferenciados; a lan, fenômeno recente, insere-se neste contexto. Trata-se de um domínio no espaço citadino que permite o acesso às novas tecnologias de comunicação em rede mediadas por computador, viabilizada e preparada, mesmo que não somente, mas principalmente, para os adoradores dos games, que são, na sua maioria, jovens.

As integrações e interações entre os jovens da lan acontecem de diversas maneiras, sendo marcante a possibilidade de "estar" em dois lugares ao mesmo tempo: interagindo com os amigos que estão na lan (lugar físico), e interagindo com o grupo que está jogando Tibia na lan e na Internet (ciberespaço).

As possibilidades de multipertencimento que se abrem aos indivíduos citadinos, já apontadas por autores como Simmel (1973), e outros interessados na temática das relações sociais no meio urbano, como Park (1973) e Wirth (1973), parece estar sendo ampliadas com o uso do computador em rede, à medida que ele viabiliza a participação dos sujeitos em dois planos de realidade, o offline (desconectado da Internet, a vida cotidiana) e o online (a vida "virtual" conectado na rede mundial). A metáfora do teatro de Goffman (1985), a qual supõe o desempenho de diversos papéis de acordo com interações específicas, expande-se, porque o "palco" de tais desempenhos é estendido para um mundo virtual, onde o self tem possibilidade de experienciar relações diferenciadas das do mundo corpóreo offline. No Tibia, como foi apontado, os jovens tornam-se guerreiros, druidas, arqueiros ou feiticeiros, e mergulham num mundo de magia e fantasia respaldados pela "proteção" dos outros personagens do game, mais poderosos, que são amigos.

Entender a "forma de integração e interação" foi a maneira mais clara que encontrei para descrever esses relacionamentos e as redes de relações que envolvem games, Orkut, MSN, moradores do bairro, disputas de poder local, rede ampla de amizades, e modos de agir característicos juvenis, como a folgação.

As particularidades de fazer um trabalho de campo entre esses jovens instigaram-me a criar alternativas que pudessem fazer essa pesquisadora, mulher, e "véia" conseguir a integração no grupo. Neste sentido, o game Tibia teve papel fundamental. Mesmo minha forma "tosca" de jogar (pois não tenho habilidades competitivas para com eles) proporcionou um laço de amizade firme e comprometido. Para além do Tibia, a folgação, uma espécie de zombaria que era uma atitude constante no modo de tratarem-se dentro do espaço da lan, 
permitiu compreender como eles configuram seus pertencimentos e a intensidade dos laços criados. Essa impressão tornou-se mais visível quando fui incluída como "amiga possível de ser folgada", quando me deram um apelido ("véia", "tia") e passaram a "folgar" em mim na lan, no Orkut, no Tibia, no MSN. Quando a familiaridade aumentou, foi necessário usar a artimanha de escrever em "código" para fazer as notas de campo, visando evitar constrangimentos, já que os jovens, costumeiramente, apanhavam a caderneta para verificar as anotações feitas.

O Tibia funciona como um "projeto em comum" (Schutz 1979; Velho 1997) de grande importância e ao qual os jovens dispensam grande parte de seu tempo. No Tibia os níveis de amizade, parcerias e proteções são construídos, mantidos ou quebrados de acordo não só com escolhas pessoais mas, a partir de uma rede de relações do mundo offline, que interfere e emana para o game. O empenho e comprometimento dos indivíduos que jogam juntos os games, garantem a diversão e excitação que são os componentes básicos do poder de fascinação da essência de qualquer jogo (Huizinga 2005). Como disse Madruga: "qualquer jogo que tenha muitos amigos fica mais divertido", e no espaço da lan house, propício a esta prática, mais ainda, pois "jogar sozinho, não tem graça".

\section{BIBLIOGRAFIA}

COSTA, Regina Soares da, 2002, Bricoleur de Rua - Um Estudo Antropológico da Cultura Hiphop Carioca. Rio de Janeiro, dissertação de mestrado em antropologia Social, Museu Nacional, Universidade Federal do Rio de Janeiro.

ELIAS, Norbert, 2000, Os Estabelecidos e os Outsiders. Rio de Janeiro, Zahar.

EPSTEIN, A. L., 1969 “The network and urban social organization”, em J.C. Mitchell (ed.),

Social Networks in Urban Situations. Manchester, Manchester University Press.

FORTIM, Ivelise, 2006, Alice no País do Espelho: o MUD - o Jogo e a Realidade Virtual Baseados em Texto, Imaginário, São Paulo, vol. 12, n. ${ }^{\circ}$ 12, Junho.

GOFFMAN, Erving, 1985, A Representação do Eu na Vida Cotidiana. Rio de Janeiro, Vozes. HISTÓRIA DO TIBIA, 2006, [online] disponível em: <www.tibiabr.com> link: A história do

Tibia (acesso em: 18-11-2006).

HUIZINGA, Johan, 2005, Homo Ludens: o Jogo como Elemento da Cultura. São Paulo, Perspectiva.

KOLO, Castulos, e Timo Baur, 2004, Living a Virtual Life: Social Dynamics of Online Gaming, Game Studies, the internacional journal of computer game research, vol. 4, n. ${ }^{\circ}$ 1, [online] disponível em: < http://www.gamestudies.org/0401/kolo/> (acesso em: 11-05-2007). 
MILLER, Daniel, e Don Slater, 2004, "Etnografia on e off-line: cibercafés em Trinidad”, em Horizontes Antropológicos, Porto Alegre, ano 10, n. ${ }^{\circ} 21$, pp. 41-65, Janeiro/Junho.

MITCHELL, J. Clyde, 1971, “The Kalela dance”, em The Rhodes - Livingstone Papers n. 27. Manchester, Manchester University Press.

PARK, Robert E., 1973, “A Cidade: sugestões para a investigação do comportamento humano no meio urbano", em Otávio Guilherme Velho (org.), O Fenômeno Urbano. Rio de Janeiro, Zahar.

PICCOLO, Fernanda Delvalhas, 2003, "Particularidades e generalizações: reflexões a partir de uma pesquisa urbana entre usuários de drogas em Porto Alegre”, em Gilberto Velho e Karina Kuschnir (orgs.), Pesquisas Urbanas. Rio de Janeiro, Zahar.

RADCliffe-Brown, A., 1973, Estrutura e Função na Sociedade Primitiva. Petrópolis, Vozes. SCHUTZ, Alfred, 1979, Fenomenologia e Relações Sociais. Rio de Janeiro, Zahar.

SIMMEL, Georg, 1973, "A metrópole e a vida mental”, em Otávio Guilherme Velho (org.), O Fenômeno Urbano. Rio de Janeiro, Zahar, 1973.

Site oficial da Prefeitura de Porto Alegre, referente ao censo de 2000, [online] disponível em: $<$ http://www2.portoalegre.rs.gov.br/spm/default.php?reg $=62 \&$ p_secao $=43>$ (acesso em: 26-08-2006).

Site da Monkey, [online] disponível em: <www.monkey.com.br> (acesso em 15-11-2006).

Site oficial do Tibia, [online] disponível em: <www.tibia.com> (acesso em 15-11-2006).

Site Tibiabr, [online] disponível em: <www.tibiabr.com> (acesso em 15-1 1-2006).

STRAUSS, Anselm L., 1999, Espelhos e Máscaras. São Paulo, EDUSP.

TOSCA, Suzana, 2002, The Everquest Speech Community. A slightly modified version of a paper presented at the Computer Games and Digital Cultures Conference, in Tampere, 2002, and printed in the proceedings edited by Tampere University Press, [online] disponível em: <http://www.it-c.dk/people/tosca/everquest.htm> (acesso em 01-07-2007).

VELHO, Gilberto, 1997, Individualismo e Cultura. Notas para uma Antropologia da Sociedade Contemporânea.Rio de Janeiro, Zahar.

— 1978 , “Observando o familiar", em Edson de Oliveira Nunes (org.), A Aventura Sociológica. Rio de Janeiro, Zahar.

—., 1973, A Utopia Urbana, um Estudo de Antropologia Social. Rio de Janeiro, Zahar.

WHITE, W. F., 2005, Sociedade de Esquina. Rio de Janeiro, Zahar.

WIRTH, Louis, 1973, "O urbanismo como modo de vida", em Otávio Guilherme Velho (org.), O Fenômeno Urbano. Rio de Janeiro, Zahar.

Between games and folgações. Anthropological notes in the lan house - Vanessa Andrade Pereira - Mestre em Comunicação e Informação, PPGCOM, FABICO-UFRGS; doutoranda, programa de pós-graduação em Antropologia Social, Museu Nacional-UFRJ • vanegaucha@gmail.com

This article wants to describe the interaction process of the anthropologist with teenagers in a lan house in Porto Alegre, Rio Grande do Sul, Brazil. First, the study will point out the peculiarities of the lan house, its location in the neighbourhood, as well as the everyday life of the young people who use this space for online playing or just for sociability. Secondly, it will discuss as youth people establish their sense of belonging and strengthen their social bounds through the folgações (joking relationships) and their online interactions in the MMORPG Tibia game. 